\title{
VARIA
}

\section{UN PROYECTO DE FRANCISCO RIZI PARA LA CÚPULA DE SAN ANTONIO DE LOS PORTUGUESES}

Desde Palomino se sabe que buena parte de la responsabilidad en la implantación del fresco como técnica de pintura mural y de la perspectiva aplicada a bóvedas y techos fue responsabilidad de Agostino Mitelli y Angelo Michele Colonna en el corto periodo que estuvieron en España, desde 1658 hasta la vuelta a Italia de Colonna en 1662, ya que Mitelli había muerto en $1660^{~}$. De sus obras practicamente no ha quedado nada, salvo el reflejo que de ella supieron captar Francisco Rizi, Juan Carreño de Miranda y Dionisio Mantuąֻ̧ entre otros.

La iglesia de San Antonio de los Portugueses, o de los Alemanes, se menciona en nuestras fuentes como obra de Francisco Rizi ${ }^{2}$ y el mismo pintor se la adjudicó en el Memorial de 1673 dirigido a la reina $\mathrm{D}^{a}$ Mariana de Austria como protesta por el ascenso de Carreño de Miranda en el escalafón de los pintores de la Corte, quedando Rizi postergado ${ }^{3}$.

La publicación de tres dibujos, adjudicados certeramente a Colonna, introdujo un nuevo giro en el problema de San Antonio y desde entonces se ha venido considerando su decora-

\footnotetext{
1 Antonio Acisclo Palomino de Castro y Velasco: El Museo pictórico y la escala óptica. Madrid, edic. Aguilar, 1947, pp. 94, 552 y 614. La vida de Mitelli y Colonna en España está narrada dentro de la de Velázquez, como responsable de su venida a Madrid (op. cit., p. 922). Sobre sus obras en España véase el artículo de Enriqueta Harris, «Angelo Michele Colonna y la decoración de San Antonio de los Portugueses», en Archivo Español de Arte, XXXIV, 1961, pp. 101-105 y III láminas. Antonio Bonet Correa, «Nuevas obras y noticias sobre Colonna», en Archivo Español de Arte XXXVII, 1964, pp. 307-312 y IV láminas. José Luis Sancho Gaspar, «El «boceto» de Colonna-Mitelli para el techo de la ermita de San Pablo», en Boletín del Museo del Pardo, VIII, n. ${ }^{\circ} 22$, 1987, pp. 32-38.

2 Palomino y Velasco, op. cit., edic, 1947, p. 1016 le atribuye «la traza y ejhecución de la arquitectura y adorno de la cúpula de San Antonio de los Portugueses», y a Carreño de Miranda «toda la historia de la bóveda y las figuras del recinto, cosa superior» (op. cit., p. 1026), si bien son conocidos los dibujos preparatorios de Rizi para la historia central, que se conservan en el Museo del Prado ' $C f r$. Alfonso E. Pérez Sánchez, Museo del Prado. Catálogo de Dibujos I. Dibujos españoles. Siglos XV-XVII. Madrid, 1972. Se trata del dibujo F.A. 91, p. 120 y lám. 53. Mide 185 x $275 \mathrm{~mm}$ y está realizado a pluma sobre papel amarillento verjurado) y en el Museo de la Casa de la Moneda de Madrid (Cfr. Reyes Durán, Catálogo de los dibujos de los siglos XVI y XVII de la colección del Museo de la Casa de la Moneda. Madrid, 1980, n. ${ }^{\circ} 60$, pp. 53 y 148. Mide 776 x 426 mm y está realizado a lápiz, repasado con tinta y aguada azul, sobre papel verjurado agarbanzado.

3 José Simón, «Francisco Rizi, postergado», en Archivo Español de Arte, XVII, 1945, p. 308. La errata del texto de la que se deduce la fecha equivocada de 1657 fue subsanada por Alfonso E. Pérez Sánchez en el catálogo de la exposición Carreño, Rizi y Herrera y la pintura madrileña de su tiempo (1650-1700), Madrid, 1985 , p. 78 .
} 
ción como obra de Rizi ${ }^{4}$, ayudado por Carreño, tal y como menciona Palomino, pero basándose en los dibujos del pintor italiano, los cuales debieron quedar en manos de los pintores del rey, pasando luego a formar parte de los álbumes del Príncipe de Asturias (futuro Fernando VII).

Ahora, la aparición de un nuevo dibujo (Fig. 1) (Madrid, colección particular) ${ }^{5}$ que muestra los rasgos caligráficos de Francisco Rizi ofrece algunas novedades para abordar de nuevo el asunto.

Como los dibujos de Colonna, el de Rizi representa un cuarto del óvalo de la cúpula que había que pintar y en este sentido es heredero del sistema del italiano. Se da a entender que las otras tres cuartas partes repiten lo fundamental, que es el esquema arquitectónico y decorativo, introduciendo santos nuevos en cada una de las hornacinas. Es un dibujo muy elaborado que, evidentemente, sucede en orden cronológico al tercer proyecto identificado por Harris, pero lo que en él se representa no se llevó en su totalidad a la práctica, especialmente en la balaustrada quebrada que encuadra el vacío dentro del cual iría el cielo con la Gloria de San Antonio. Respecto al dibujo de Rizi para este asunto central, conservado en la Casa de la Moneda de Madrid, hay que señalar que este vacío central presenta perfiles no coincidentes, pues mientras en el dibujo de arquitectura los extremos semicirculares son más estrechos que el tramo central, en el dibujo de la Gloria ocurre lo contrario. Es sin duda un tanteo para la obra definitiva, que finalmente se realizó con una forma ovalada, acorde con la planta del edificio.

Pero no es la única variante. Rizi planteó el esquema general de la pintura sobre la cornisa arquitectónica de la iglesia como un tambor de dos cuerpos rematado por un sofito de ménsulas, casetones y cartelas de amplia decoración carnosa, tambor sobre el cual monta una balaustrada en perspectiva jalonada de trecho en trecho por pilares rematados con bolas. Los lunetos con las ventanas rectangulares acabadas en un segmento de arco son el elemento de arquitectura real que el pintor tuvo que respetar y su acristalamiento está perfectamente definido.

El cuerpo bajo del tambor fingido contiene en este dibujo novedades desconocidas en los proyectos de Colonna y quizá no realizadas en la obra definitiva, salvo que las restauraciones de Luca Giordano en $1699^{6}$ las modificara en mayor medida de la que desearíamos imaginar. Sobre unas poderosas ménsulas, muy decoradas con festones de frutas colgando por sus delanteras y ángeles niños antepuestos a las lunetas laterales de las ventanas, se elevan dos poderosas columnas de fuste liso con capitel jónico sobre un equino de gruesas ovas. El conjunto se remata con un entablamento de cornisa en fuerte voladizo, coronada por las volutas de un frontón partido, sobre cuyos lomos se recuestan dos angelitos sosteniendo un florero que se encaja en el seno del frontón. Las columnas enmarcan hornacinas aveneradas, dentro de las cuales están representados San Pablo y San Juan Bautista descansando sobre un basamento con parejas de ángeles niños. Se trata de una iconografía distinta a la de los santos y beatos de origen portugués que finalmente se impuso y cuya rareza necesitó de un letrero identificativo. Las velas del luneto, con su profusión de roleos, festones y querubes, aun dejan en sus centros espacio para otras representaciones figurativas, esbozadas con diminutas figurillas de imposible identificación.

4 Harris, op. cit., 1961.

5 Mide 42 × $25 \mathrm{cms}$. aprox. Está realizado a lápiz, repasado a tinta sepia y toques de aguada gris, sobre papel verjurado amarillento.

6 Sobre el proceso decorativo del interior de San Antonio hasta 1702 véase el artículo de Ismael Gutiérrez Pastor y José Luis Arránz Otero, «La decoración de San Antonio de los Portugueses (1660-1702)», en Anuario del Departamento de Historia y Teoría del Arte (U.A.M.), vol. XI, 1999 (en prensa). 
Sobre los lunetos se adivina la estructura del ático de este tambor de hornacinas entre columnas y ventanas. Sobre las columnas Rizi ideó unas pechinas trapezoidales, compartimentadas por la presencia de querubes con las alas plegadas al tronco y extremidades inferiores en forma de ménsula arquitectónica, que recuerdan las formas de Borromini en sus decoraciones romanas ${ }^{7}$. Encuadran estas pechinas arcos de medio punto, con el intradós decorado por una palma trenzada, que dan paso hacia una serie de estancias profundas y abiertas hacia un espacio luminoso para sugerir luz sobre la superficie cerrada de la cúpula. Sobre la balaustrada, a contraluz, aparecen parejas de ángeles sentados, portando coronas de laurel, semejantes a los del dibujo para la decoración de una cúpula (Madrid, Academia de San Fernando), que Bonet Correa no llega a atribuir del todo a Colonna ${ }^{8}$.

El dibujo se cierra con el trazado de la cornisa y la balaustrada de perfil mixtilíneo, con los extremos semicirculares unidos al tramo recto del centro, correspondiendo con el lado largo de la planta elíptica, trazado que finalmente fue alterado en la pintura definitiva.

La pintura actual (Fig. 2), con los repintes y restauraciones de Giordano, distorsiona algo su comparación con el dibujo. Como recuerda Palomino, Giordano transformó en salomónicas las columnas lisas ${ }^{9}$. Todo el zócalo bajo estas columnas, con sus ángeles niños sosteniendo las bandejas ovaladas y ochavadas que imitan relieves de bronce, es también obra de Giordano. Su intervención en esta zona de la cúpula hizo que desapareciera lo pintado por Rizi y Carreño, que quizá no respetaba este dibujo, como no se respeta en el tipo de hornacina enmarcada por las columnas, ni su iconografía, ni la uniformidad en la decoración de las velas, donde finalmente alternaron cúpulas ciegas y cartelas con las virtudes cardinales y ángeles mancebos recostados sobre sus nervios. Sí están en la obra final los frontones curvos partidos con sus niños sobre el lomo y sus jarrones, pero el desarrollo de este cuerpo se ha visto reducido en altura, desapareciendo los triángulos trapezoidales, y las arquerías que abren las arquitecturas son ciegas. La balaustrada mixtilínea fue sustituida por un gran entablamento ovalado con friso de roleos carnosos, al cual se le superpusieron tres grandes cartelas fingidas de color ocre amarillo, imitando bronce dorado, la más importante de las cuales se sitúa sobre el acceso a la iglesia y representa las armas del reino de Portugal rodeadas por una bordura de castillos (reino de Castilla), completada con ángeles dorados y otros de colores naturalistas portando coronas de laurel, muestra indudable del estilo pictórico de Rizi.

En relación con los dibujos de Colonna, parece que Rizi aprovechó partes del dibujo II ${ }^{10}$, como las cartelas sobre las ventanas, donde finalmente irían las virtudes cardinales, y la idea de la cornisa fingida ovalada con el friso de roleos y cartelas sobrepuestas, levemente modificadas en su aspecto definitivo. Del dibujo III ${ }^{11}$, los templetes de las dobles columnas lisas es lo más notable de lo considerado por Rizi, si bien en Colonna no hay representaciones figuradas. En todos los proyectos de Colonna el pintor hizo hincapié en la heráldica portuguesa, dado el carácter de la institución que se trataba de decorar. Cuando Rizi y Carreño

${ }^{7}$ Estos ángeles se repiten, vistos de perfil, en el dibujo para una decoración teatral o para un festejo real de la Biblioteca Nacional de Madrid (Barcia 458) (Cfr. Dibujos de arquitectura y ornamentación de la Biblioteca Nacional. Siglos XVI y XVII. Madrid, 1991, p. 74, n. ${ }^{\circ} 93$ ).

8 Bonet Correa, op. cit., 19.., p. 311.

9 Palomino y Velasco, op. cit., edic. 1947, pp. 1111-1112.

10 Véase Harris, op. cit, 1961, lámina II.

"Ibidem, lámina III. 

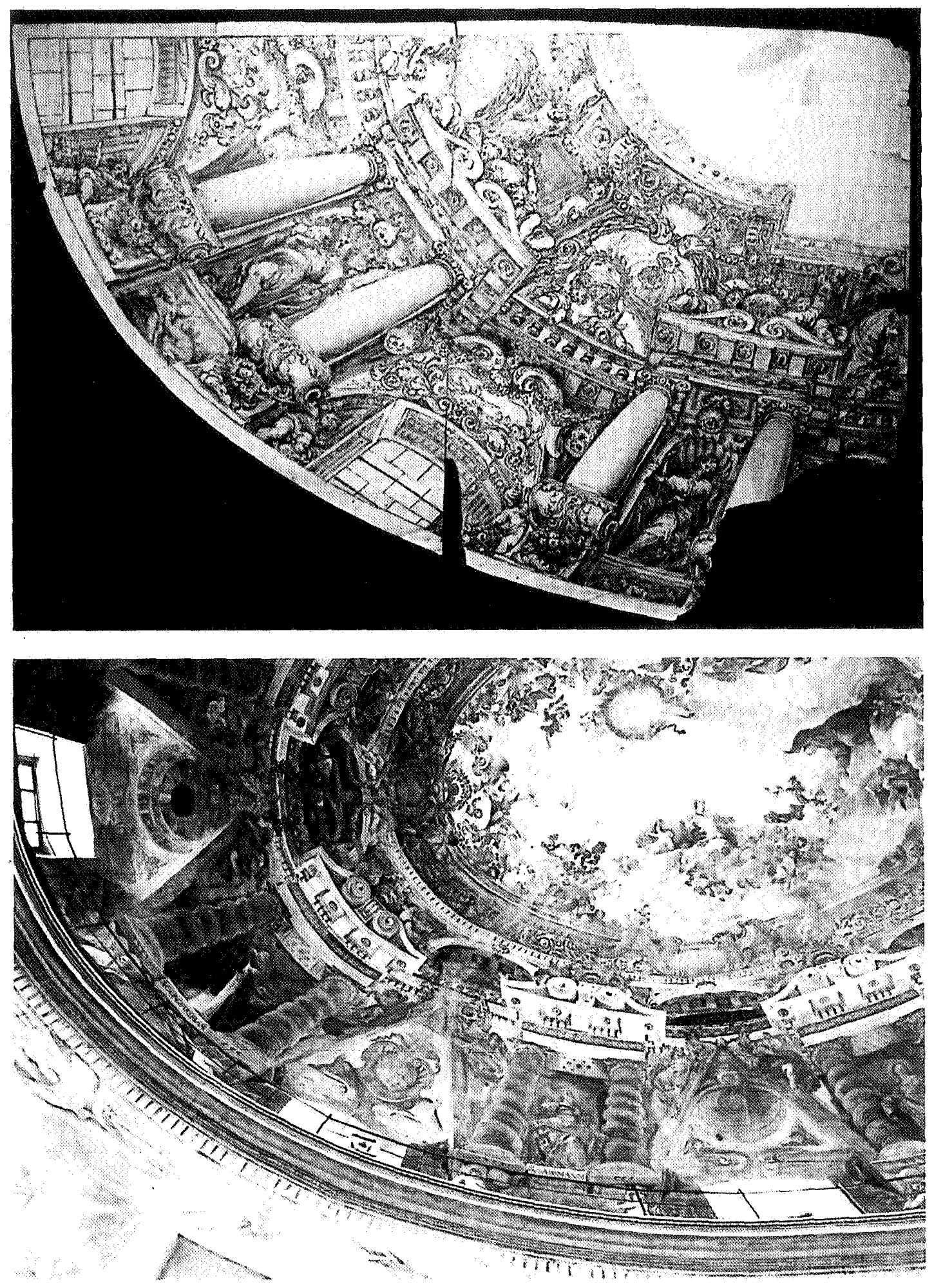

Figura 1. Francisco Rizi: Dibujo para Cúpula San Antonio de los Portugueses. Madrid. (Colección particular). Figura 2. Luca Giordano: Cúpula San Antonio de los Portugueses. Madrid. 
abordaron los trabajos definitivos de la pintura hacia $1662-1663^{12}$, estos recuerdos portugueses, que ya campeaban en el retablo mayor de la iglesia ${ }^{13}$, fueron suprimidos.

Los primeros tanteos para la decoración de San Antonio estaban ya en marcha en 1660 y es problable que la vuelta de Colonna a Italia en 1662 supusiera una detención en el ritmo de los trabajos que luego retomarían Rizi y Carreño, quienes habían colaborado con el italiano en el Alcázar Real y en el Buen Retiro. Ambos pintores recibieron pagos en 1663, pero la obra debió ir lenta, hasta que en 1666 la falta de medios económicos obligó a la Hermandad a suspender la obra cuando la cúpula ya estaba terminada, desistiendo en su idea inicial de pintar también los muros de la iglesia ${ }^{14}$. En distintas fechas los pintores habían ido recibiendo cantidades de 3.000 reales: el 21 de septiembre y el 11 de noviembre de 1663 ; el 21 de enero de 1664; el 25 de agosto y el 4 de octubre de 1665 y el 21 de febrero de 1666, por todas cuyas cantidades dieron carta de pago el 12 de diciembre de $1665^{15}$, que se sumaban a los 31.558 reales recibidos en $1663^{16}$. Aunque las sumas no cuadran completamente, consta por resúmenes de cuentas de la Hermandad que el gasto de toda la pintura ascendió, con la cúpula acabada, a 61.730 reales ${ }^{17}$.

ISMAEL GUTIÉRREZ PASTOR Universidad Autónoma de Madrid

\section{ENTRE LA VIDA Y LA MUERTE. $=6$ NUEVAS APORTACIONES DOCUMENTALES SOBRE VELÁZQUEZ EN SEVILLA}

Los documentos descubiertos en los dos últimos años sobre Velázquez por diferentes investigadores están ayudando a conocer mejor la vida y obra del pintor, todavía repleta de sombras en cuanto a su personalidad. Este artículo recoge las últimas contribuciones docu-

12 Sobre la cronología de las pinturas de Rizi y Carreño en San Antonio de los Portugueses, las dudas y fechas relativas expuestas por Tormo y por Angulo Iñiguez, así por quienes han seguido sus textos, han sido parcialmente renovadas por el Conde de Tepa, Breve historia de la Santa, Pontificia Hermandad del Refugio y Piedad de Madrid. Madrid, 1995, pp. 35-36, donde transcribe parcialmente algunos acuerdos de la Hermandad de San Antonio. Y con mayor precisión por Gutiérrez Pastor-Arranz Otero, op. cit., 1999 (en prensa).

${ }_{13}$ El retablo mayor con los lienzos de Vicente Carducho y la imagen de San Antonio de Padua de Manuel Pereira había sido contratado por Juan Bautista Garrido en 1630, pero en 1631 se agrandó, extendiéndolo fuera del arco del presbiterio por las paredes laterales, siendo obra de Miguel Tomás. Llegaba hasta la"cornisa del templo y en las enjutas entre la estructura y el arco había dos escudos de Portugal ( $C f r$. Gutiérrez Pastor-Arranz Otero, op. cit., 1999 (en prensa).

${ }_{14}$ En 1660 la Hermandad de San Antonio ya tenía intención de pintar totalmente el interior de la iglesia. En 1661 las obras parece que llevaron buen ritmo, pero hasta el 31 de julio de 1663 no consta el pago a Rizi y a Carreño de 31.558 reales. El 22 de marzo de 1665 se esperaba poder «acabar de pintar la iglesia» (no la cúpula) y el 18 de julio de 1666 la Hermandad acordó que no se prosiguiera la pintura «de cornisa para abajo, en la conformidad que está hecha de pintura (sic) para arriba» dada la falta de medios (Archivo de la Santa Real Pontificia Hermandad del Refugio. San Antonio. Legajo 517, libro 2 (1656) de Actas de la cofradía de San Antonio, fols. 14-14 v. ${ }^{\circ}, 19,20-20$ v. $^{\circ}$ y sin foliar las siguientes referencias. Cfr. Gutiérrez Pastor-Arranz Otero, op. cit., 1999 (en prensa).

is Archivo Histórico de Protocolos. Madrid. Protocolo 8973, fols. 781-781 v.‥

16 Archivo Histórico de Protocolos. Madrid. Protocolo 8973, fols. 370-370 v. .

17 Archivo Histórico Nacional. Madrid. Consejos, legajo 17.221. 